\title{
A SIMPLE METHOD OF ARTERIAL CANNULATION
}

\author{
Davi Evans, M.B., CH.B., F.R.C.P.(c), AND SIDNEY OZER, M.D., F.R.C.P.(c)
}

MONITORING THE BLOOD PRESSURE directly by arterial cannulation has become a necessary requirement in many clinical situations, and we find it especially useful during and after major surgery such as cardiovascular and neurosurgical procedures. A major problem in the past has been the development of a technique which $(a)$ does not necessitate cutting down on the vessel, $(b)$ is uncomplicated and fast, and $(c)$ has a success rate equivalent to that obtained with routine intravenous cannulation. We have achieved these criteria by a method suggested initially by one of us (S.O.).
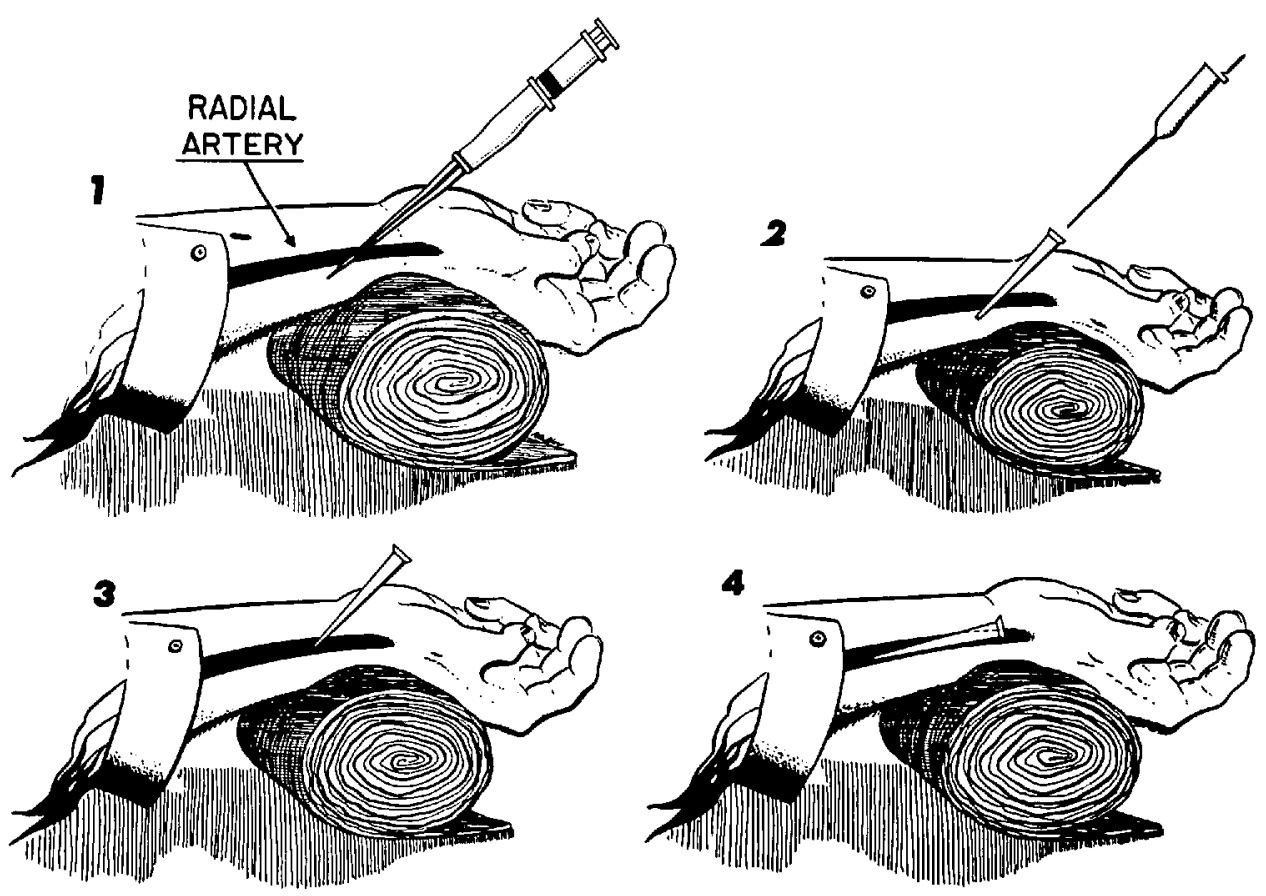

Figure 1

The selection of a cannula is of some importance, a id this is certainly a matter of individual preference. However, after much trial a: $l$ error we selected the \#18 "Argyle" Medicut $\dagger$ cannula-stilette-syringe complex, the same as that generally used in the hospital for intravenous cannulation. Its main advantages are that it is of simple construction and is familiar to all the staff and residents. Its main

"Department of Anaesthesia, University of Toronto, and the Toronto Western Hospital.

†Made by Brunswick Corporation.

Canad. Anaesth. Soc. J., vol. 17, no. 2, March 1970 
disadvantage is that it lacks a Luer Lok connector at its proximal end, a situation we hope will be remedied in the near future.

Although almost any palpable artery is suitable for cannulation, we invariably use the radial artery. There have been no complications using this vessel even when the ulnar artery has not been palpable. The wrist is extended over a towel or small bolster and the fingers, also extended, are taped to the arm board. The artery is palpated and the cannula-stilette complex is passed through the skin and the artery at an angle of $45-60^{\circ}$ (Fig. 1 (1)).

We have found it an important part of the technique not to attempt to locate the artery during this manoeuvre by withdrawing on the syringe. If only the stilette and not the cannula is in the vessel withdrawal of the former will lead to haematoma formation and arterial spasm. (Actually the syringe is superfluous to the technique, being used only to keep the stilette firmly in the cannula.)

The stilette is then removed (2) and the cannula withdrawn until the tip lies in the vessel (3). This will be obvious by the pulsatile flow of blood. Without capping the proximal end, the cannula is threaded up the vessel (4), and only then is a stopcock attached. It is important to obtain a good pulsatile flow at all times, and an undamped tracing can be confirmed by visualizing the pressure curve on the oscillograph.

Occasionally the initial puncture results only in a very sluggish flow of blood. In this situation we have found it better to leave this cannula in situ and attempt another cannulation with a new Medicut a little further proximally. If the initial cannula is withdrawn it invariably results in haematoma formation and arterial spasm, which makes even a cut-down technique difficult. 